D.O.I.: $10.3895 / \mathrm{S} 1808-04482006000300009$

\title{
IMPACTOS ORGANIZACIONAIS DA ADOÇÃO DE NORMAS ISO 9000: ESTUDOS DE CASOS NA CADEIA DE EMBALAGENS PET PARA BEBIDAS
}

\section{ORGANIZATIONAL IMPACTS FROM THE ADOPTION OF ISO 9000 NORMATIVE STANDARDS: CASE STUDIES IN THE PET PACKAGING CHAIN}

\author{
Milena Yumi Ramos ${ }^{1}$; Roberto Sbragia ${ }^{2}$ \\ ${ }^{1}$ Fundação de Amparo à Pesquisa do Estado de São Paulo - FAPESP - São Paulo - Brasil \\ myramos@,fapesp.br \\ ${ }^{2}$ Universidade de São Paulo - USP - São Paulo - Brasil rsbragia@usp.br
}

\begin{abstract}
Resumo
Os objetivos centrais deste estudo foram caracterizar a dinâmica de adoção do padrão normativo ISO 9000 e analisar seus impactos em aspectos internos e externos da empresa. Em relação ao primeiro ponto, investigaram-se os principais indutores da adoção de tal padrão, dificuldades enfrentadas durante sua implementação, lacunas identificadas e iniciativas complementares adotadas após a certificação; e, quanto ao segundo, as principais mudanças estratégicas, gerenciais, operacionais e nos relacionamentos com fornecedores e clientes diretos percebidas, especialmente no que tange às funções Tecnológica e Qualidade. A investigação dessas questões envolveu o estudo de dois casos - os maiores produtores de resina e garrafas PET instalados no Brasil. A análise comparativa dos casos revelou, em geral, diferentes perfis de adoção da ISO 9000 e impactos decorrentes, excetuando-se o fato de que se concentraram na esfera produtiva. Uma explicação encontrada para tal resultado está ligada à existência de um programa de qualidade que ultrapassa o escopo e os limites da ISO 9000 e de uma cultura para a qualidade no caso do fabricante de resina, mas não no de garrafas PET. Outra se refere à intensidade e diversidade da atividade cooperativa dessas empresas com parceiros diretos da cadeia de valor, significativamente superior no primeiro caso relativamente ao segundo. E uma terceira, diz respeito à atuação de vários fatores intervenientes, nomeadamente a nacionalidade da matriz e o elo da cadeia. Comparações preliminares com estudos similares nacionais e internacionais permitiram verificar, em caráter exploratório, que fatores locais de natureza setorial, socioeconômica e de infra-estrutura institucional de apoio interferem na relação entre adoção das normas ISO 9000 e suas implicações para a empresa, mas não determinam a existência de variadas "versões" de sistemas de gestão da qualidade construídos com base nesse padrão.
\end{abstract}

Palavras-chave: mudança organizacional; normas ISO 9000; embalagens PET; garantia da qualidade. 


\section{Introdução}

No Brasil, o movimento de abertura comercial iniciado em meados dos anos de 1990, no sentido de criar um ambiente concorrencial de forte rivalidade entre as empresas, tornou-se fator propulsor do aumento da competitividade da indústria nacional. Por um lado, no sistema financeiro, a retomada do acesso aos fluxos internacionais de capital, após a crise da dívida nos anos 80, estimulava o investimento industrial; por outro, a entrada de empresas transnacionais com capacidade de liderar a governança local pressionava as empresas nacionais a inserirem-se nas cadeias globais, sob a condição de que obedecessem a determinados padrões de fornecimento.

A operacionalização de sistemas de gestão e garantia da qualidade segundo normas técnicas internacionais passou a fazer parte, com freqüência, desses padrões. Dentre essas normas, tornou-se muito difundida, entre diversas indústrias de vários países, as da série ISO 9000, um conjunto de regras explícitas que estabelecem requisitos e procedimentos em aspectos de saúde, segurança ou outros atributos desejados de materiais e artefatos utilizados em processos industriais ou em produtos resultantes do processamento industrial (STEINMULLER, 2003) .

Formuladas em regime híbrido público-privado por comitês internacionais, representam, em termos macroeconômicos, importantes fatores a favor da (ou, em alguns casos, contra a) eficiência da economia e do comércio mundial. Já nas cadeias de valor, exercem o papel de controle da interação local/global entre as empresas, que as adotaram por indução de forças de mercado, bem como de suporte formal a processos organizacionais internos (organização do trabalho, comunicação, treinamento, etc.) e externos (poder de compra da empresa, indução de transferência de tecnologia, etc.).

Particularmente na cadeia de embalagens PET para bebidas, a pressão competitiva e a difusão das normas de garantia da qualidade ISO 9000 aliaram-se a outros fatores, impulsionando upgradings na esfera de produção. A introdução do polietileno tereftalato (PET) como novo material de embalagem para bebidas carbonatadas não-alcoólicas, em substituição ao vidro, em meados dos anos de 1990, representou uma inovação tecnológica significativa, que desencadeou alterações relevantes na estrutura industrial do setor. A substituição do material de embalagem, afetando a estrutura logística e os custos de produção e de transação da cadeia, possibilitou a formação de dois grupos distintos de competidores: poucas grandes empresas globais, que competem em marca e qualidade; e muitas pequenas empresas regionais, que competem em preço.

Estimulada pela demanda crescente por alimentos e bebidas já acondicionados em embalagens PET em grande escala (refrigerantes), em pequena escala (água mineral, sucos, sumos concentrados, isotônicos, energéticos, óleos comestíveis, entre outros), ou ainda como possibilidade futura (cervejas), a nova estrutura de fornecimento desse tipo de embalagens no Brasil estimulou a 
produção nacional de resina PET, anteriormente toda importada e utilizada para outros fins (produção de fibras e filmes plásticos). O aquecimento do mercado brasileiro, de grandes proporções, e a possibilidade de atender ao mercado sul-americano favoreceram a entrada de transnacionais e a implantação de instalações locais de produção. A adição da dimensão global no modo de produção e competição no setor refletiu-se na utilização de padrões internacionais de garantia da qualidade, como os da série ISO 9000, entre outros instrumentos, para a coordenação dessa cadeia produtiva.

Considerando-se a carência de resultados e indícios capazes de fornecer uma caracterização mais ampliada dos impactos intra-organizacionais, abrangendo mudanças estratégicas, gerenciais e operacionais, e, sobretudo, interorganizacionais, envolvendo o relacionamento entre parceiros diretos na cadeia de valor, associados à adoção da ISO 9000 no setor em questão, e em função da adaptação dessas empresas a esse novo cenário, a cadeia de embalagens PET para bebidas constituiu-se em um interessante e adequado universo de análise, sobre o qual as seguintes questões foram investigadas:

a) por que a empresa decidiu implantar um sistema de gestão da qualidade certificado pela norma ISO 9000?

b) como foi o processo de implantação e certificação do sistema de gestão da qualidade?

c) como a adoção do padrão normativo ISO 9000 afetou aspectos internos relacionados à estratégia, gestão e operações na empresa?

d) como a adoção do padrão normativo ISO 9000 afetou aspectos externos, associados aos relacionamentos com parceiros diretos da cadeia de valor?

Tendo em vista responder a estas questões, o artigo foi organizado, além desta introdução, em quatro outras seções. Na seção 2, expõem-se as proposições e premissas assumidas, destacando o eixo teórico-conceitual do estudo, baseado na influência da adoção de normas técnicas, especialmente as da série ISO 9000, sobre aspectos internos e externos da empresa. Explicitam-se, também, as variáveis independente (adoção do padrão normativo ISO 9000), dependente (impactos intra e interorganizacionais decorrentes da adoção do padrão normativo ISO 9000) e intervenientes (elo da cadeia e nacionalidade da matriz) analisadas, além de uma breve caracterização das empresas investigadas e dos métodos de pesquisa utilizados.

A seção 3, subdividida em três subseções, trata: a) dos motivos para a adoção desse padrão para a gestão do sistema da qualidade, das dificuldades e das lacunas detectadas durante os processos de implantação, bem como dos esforços de absorção dos princípios fundamentais das normas ISO 9000; b) das mudanças em aspectos estratégicos, gerenciais e operacionais, sobretudo associadas às Funções Tecnológica e da Qualidade; c) da atividade de cooperação, especialmente na dimensão tecnológica, com agentes da cadeia de valor, considerando o tipo de relacionamento, a 
forma de oficializá-lo, as áreas implicadas nas atividades desenvolvidas em conjunto, e elementos negociados nesses relacionamentos.

Na seção 4, por fim, apresenta-se uma síntese dos resultados obtidos, considerados à luz das proposições previamente assumidas e das limitações do estudo, bem como os desdobramentos relativos ao tema e recomendações para trabalhos futuros em torno da problemática focalizada, a serem desenvolvidos com maior rigor metodológico e representatividade.

\section{Estrutura conceitual e analítica do estudo}

A literatura fornece indicações de que o estudo da adoção de novas tecnologias, considerando esta como variável independente ou causal, não tem sido comum. Ao contrário, observam-se trabalhos que a consideram um efeito positivo do progresso técnico e de pressões econômicas; e as pesquisas em normas técnicas normalmente concentram-se em seu processo de adoção e implantação, bem como nos resultados produtivos e mesmo financeiros decorrentes.

Nesse sentido, diversos estudos têm identificado impactos positivos da difusão das certificações ISO 9000 sobre a capacitação produtiva de empresas industriais (GOTZAMANI; TSIOTRAS, 2002; MESSEGHEM, 2001; SZYSZKA, 2001; ROTH, 1998; VONDEREMBSE; WHITE, 1996). Alguns deles reportam melhora do controle gerencial e aumento na eficiência dos procedimentos, uma vez que estes são mais claramente entendidos e incorporados nas rotinas operacionais da organização. Outros ressaltam as relativas vantagens da implantação das normas ISO 9000 vis-à-vis outros padrões de gestão da qualidade, além de tornarem mais favoráveis às empresas certificadas por esta norma as condições para implantar outras técnicas de melhoria da qualidade e assim fortalecer sua estratégia promocional e atender melhor aos clientes.

Tais evidências indicam que a relação entre difusão das normas ISO 9000 entre as empresas industriais e sua capacitação produtiva tem sido extensamente estudada no caso brasileiro. Alerte-se que tal literatura apresenta um foco intra-empresarial claro, deixando relativamente descobertas questões associadas aos relacionamentos entre as empresas. Outra lacuna identificada a partir desses estudos diz respeito à incorporação dos princípios nas rotinas organizacionais, uma vez que raramente enfocam o processo de absorção e impactos de longo prazo, por exemplo, na capacitação tecnológica e de relacionamento com parceiros da cadeia de valor.

Alguns autores (FIGUEIREDO, 2001; SZYSZKA, 2001; WOLFE, 1994; HOFFMAN, 1989 apud FIGUEIREDO, 2001; ROGERS, 1983, etc.), no entanto, têm alertado para essas lacunas e para a necessidade de pesquisas que as respondam, e outros (QUADROS, 2002; NADVI; 
WÄLTRING, 2001; NADVI; KAZMI, 2001; HUMPHREY; SCHMITZ, 2000, entre outros) ${ }^{1}$ iniciaram recentemente tal tarefa. Acerca dessa questão, Quadros (2002), Humphrey e Schmitz [2001?] e Nadvi e Wältring (2001) apontaram que a difusão de normas de processo em garantia da qualidade poderia contribuir para o aperfeiçoamento organizacional e o fomento à capacitação tecnológica de fornecedores de insumos, partes e componentes, possibilitando à indústria ampliar e intensificar relacionamentos externos.

Mais especificamente, Nadvi e Kazmi (2001) indicaram os processos de fornecimento e de pesquisa e desenvolvimento (P\&D) como aqueles em que os efeitos da difusão de normas ISO 9000 seriam mais significativos e variados: desde a redução na intensidade de colaboração interorganizacional na área de produção, envolvendo apenas a contratação limitada de fornecimento, até o aprofundamento da colaboração entre empresas para além da área de produção, englobando as áreas de design, desenvolvimento, marketing e distribuição.

No primeiro caso, a colaboração possibilitaria, de acordo com Madhok (1998), uma maior eficiência em custos, seja pela redução dos mesmos, seja pela criação de valor na atuação conjunta. Tais sinergias decorreriam da combinação única de recursos e capacitações dos parceiros, num arranjo de difícil aquisição ou imitação. No segundo, as empresas parceiras se beneficiariam, conforme apontam Dyer e Singh (1998), da facilitação de acesso a recursos individualmente escassos, mas que, conjuntamente, poderiam ser criados, compartilhados e geridos de forma única para superar barreiras à entrada em novos mercados e entraves ao crescimento em mercados já atendidos.

Entretanto, os possíveis desdobramentos intra e interorganizacionais associados à adoção das normas ISO 9000 pela empresa podem sofrer a influência de fatores intervenientes ambientais e setoriais. Com base em estudos nesse tema, estima-se que dois dentre tais fatores são especialmente importantes em análises de casos específicos como os que se enfocaram neste estudo: o elo da cadeia de valor de embalagens PET para bebidas a que a empresa pertence e a nacionalidade da matriz.

Considerando aspectos de governança da cadeia, seja com características hierárquicas, acompanhados de desigualdades de poder e influência e maior propensão a uma cooperação limitada (em atividades acessórias), seja com características de rede, em que há maior homogeneidade de poder e influência e maior propensão a uma cooperação ampliada (em atividades-chave), a análise segundo o elo a que a empresa pertence pode revelar semelhanças e diferenças importantes entre elos distintos.

\footnotetext{
${ }^{1}$ Esses e outros autores do projeto "The interaction of global and local governance: implications for industrial upgrading", do grupo de trabalho para estudos em globalização do Institute for Development Studies (IDS) - University of Sussex, Reino Unido têm realizado estudos teóricos e empíricos no sentido de cobrir as lacunas acima apontadas.
} 
Já levando em conta o papel do contexto socioeconômico e da infra-estrutura institucional de apoio, facilitando ou obstaculizando a difusão de novas tecnologias, e afetando igualmente seus efeitos no conjunto das empresas, a análise da nacionalidade da matriz pode fornecer indícios relevantes quanto ao modo como as variáveis dependente e independente definidas neste estudo são influenciadas por fatores macroambientais.

À luz dessas considerações, duas proposições para investigação foram formuladas:

a) a contribuição da adoção do padrão normativo ISO 9000 para o aperfeiçoamento produtivo, tecnológico e organizacional da indústria pode ser afetada, dependendo da estrutura de governança da cadeia e do contexto socioeconômico e infra-estrutura institucional de apoio, pelo elo a que a empresa pertence e pela nacionalidade da matriz, respectivamente;

b) a contribuição da adoção do padrão normativo ISO 9000 para o aprofundamento dos relacionamentos com parceiros diretos da cadeia de valor, seja em aspectos técnicoprodutivos, seja em atividades-chave da cadeia (tais como marketing, design, P\&D e distribuição) pode ser afetada, dependendo da estrutura de governança da cadeia e do contexto socioeconômico e infra-estrutura institucional de apoio, pelo elo a que a empresa pertence e pela nacionalidade da matriz, respectivamente.

O universo sobre o qual recaiu a análise de tais proposições, como destacado anteriormente, são as empresas industriais que pertencem à cadeia de embalagens PET para bebidas instaladas no Brasil. Mais especificamente, aquelas cadeias formadas por empresas localmente instaladas, detentoras de certificado ISO 9000 válido no momento da coleta dos dados, que fornecem insumos diretos ou indiretos para produtores de bebidas de marcas globais, em que a concorrência é pela marca e pela qualidade.

Tendo em vista os critérios de seleção utilizados na pesquisa e o retorno favorável das empresas contatadas, foram escolhidas duas empresas para estudos de caso, ambas de grande representatividade, em termos de volume de produção e de participação relativa, no mercado brasileiro de resina e pré-formas/garrafas PET.

Certificada pela ISO 9001: 2000, a planta industrial do fabricante de resina PET localiza-se na região Sudeste do Brasil e iniciou suas operações em 1975. Em 2003, a planta tinha capacidade para produzir 200 mil toneladas de resina PET, empregava 424 pessoas e obteve uma receita líquida de vendas de quase $\mathrm{R} \$ 900$ milhões, dos quais 17,6\% provieram de exportações. Esta empresa indicou o Assistente de Qualidade Sênior para responder ao formulário da pesquisa; já a planta industrial do fabricante de pré-formas, produto intermediário na produção da garrafa PET, certificada pela ISO 9002: 2000, localiza-se na região Nordeste do Brasil, e iniciou suas operações em 1989. Dados consolidados para 2003 revelaram que a indústria empregava 455 pessoas e obteve 
receita líquida de vendas da ordem de $\mathrm{R} \$ 200$ milhões. A empresa não apresenta atividade de exportação, mas em nível nacional, atua em diversas regiões. Foi indicado o Analista de Qualidade para responder ao formulário da pesquisa.

Estas duas empresas receberam formulários eletrônicos na forma de survey ${ }^{2}$, constituídos de seis seções. As de número um a três colhiam informações para a identificação do formulário e da empresa; a de número quatro era formada por questões que buscavam caracterizar a empresa e a cadeia de valor na qual a mesma se inseria; a de número cinco tratava da dinâmica de adoção das normas ISO 9000 pela empresa; e a de número seis dedicava-se à caracterização dos impactos internos em aspectos estratégicos, gerenciais e operacionais decorrentes da certificação, bem como dos relacionamentos da empresa com seus principais fornecedores e clientes diretos.

Esquematicamente, a estrutura analítica do estudo pode ser representada como mostra o Quadro 1.

\footnotetext{
${ }^{2}$ Constitui-se em um processo legítimo e científico de coletar dados e opiniões a partir de um público definido. Os pesquisadores buscam determinar a opinião ou percepção do público com relação a produtos, questões específicas e outros tópicos. Existem diversas técnicas de se coletar dados através de surveys, todas envolvendo o questionamento dos entrevistados: pessoalmente, por telefone, por correio (postal ou eletrônico) ou via Internet. Em geral, há dois tipos de questões que o pesquisador pode utilizar para extrair as informações dos entrevistados: as estruturadas e as não estruturadas. Nas questões estruturadas, são fornecidas alternativas ao entrevistados, das quais ele apenas escolhe uma ou mais, conforme o objetivo da questão. Nas questões não estruturadas, os entrevistados redigem um texto acerca do que é perguntado, requerendo que a questão seja elaborada cuidadosamente em termos de clareza e exatidão.
} 
Quadro 1 - Estrutura analítica do estudo

\begin{tabular}{|c|c|c|}
\hline Variável & Definição operacional & Indicadores \\
\hline \multicolumn{3}{|l|}{ Principal } \\
\hline $\begin{array}{l}\text { Adoção e absorção de normas } \\
\text { técnicas de processo em } \\
\text { garantia da qualidade série } \\
\text { ISO } 9000\end{array}$ & $\begin{array}{l}\text { Representa a dinâmica de } \\
\text { seleção e incorporação do } \\
\text { padrão normativo ISO } 9000 \\
\text { entre as empresas selecionadas }\end{array}$ & $\begin{array}{l}\text { - Indutores da adoção do padrão ISO 9000; } \\
\text { - Necessidades da empresa e dos clientes a serem } \\
\text { atendidas; } \\
\text { - } \quad \text { Dificuldades enfrentadas para a obtenção do } \\
\text { certificado; } \\
\text { - } \quad \text { Lacunas na gestão da garantia da qualidade; } \\
\text { - } \quad \text { Certificações e práticas complementares adotadas } \\
\text { em garantia da qualidade. }\end{array}$ \\
\hline
\end{tabular}

\begin{tabular}{|c|c|c|}
\hline Impactos organizacionais & $\begin{array}{l}\text { Representam as mudanças } \\
\text { percebidas em aspectos internos } \\
\text { e externos das empresas } \\
\text { selecionadas, em função, } \\
\text { parcialmente e sob a influência } \\
\text { de fatores intervenientes, da } \\
\text { adoção do padrão ISO } 9000\end{array}$ & $\begin{array}{l}\text { - Avaliação das mudanças quanto ao nível de } \\
\text { qualidade dos produtos e a produtividade/eficiência } \\
\text { dos processos; } \\
\text { - Avaliação das mudanças quanto ao papel da } \\
\text { qualidade na estratégia de negócios, quanto à política } \\
\text { de qualidade, quanto à estrutura e aos processos } \\
\text { administrativos e sistemas de gestão, e quanto aos } \\
\text { procedimentos operacionais em gestão da qualidade; } \\
\text { - Avaliação das mudanças na capacitação do } \\
\text { pessoal envolvido na gestão do sistema da qualidade; } \\
\text { - Avaliação das mudanças quanto à estratégia, } \\
\text { capacitação e especialização tecnológica da empresa; } \\
\text { - Avaliação das mudanças no comportamento do } \\
\text { cliente e do fornecedor; } \\
\text { - Avaliação das mudanças quanto às atividades } \\
\text { realizadas em cooperação e às questões negociadas } \\
\text { entre os parceiros; } \\
\text { - Avaliação das mudanças quanto à política de } \\
\text { relacionamento com parceiros da cadeia de valor. }\end{array}$ \\
\hline \multicolumn{3}{|l|}{ Interveniente } \\
\hline Nacionalidade da matriz & $\begin{array}{l}\text { País em que se localiza a matriz } \\
\text { das empresas selecionadas }\end{array}$ & $\begin{array}{l}\text { País em que se localiza a matriz das empresas } \\
\text { selecionadas }\end{array}$ \\
\hline Elo da cadeia de valor & $\begin{array}{l}\text { Categoria de produtor das } \\
\text { empresas selecionadas, } \\
\text { relativamente ao produto que } \\
\text { fabrica }\end{array}$ & $\begin{array}{l}\text { Fabricantes de resina } \\
\text { Fabricantes de pré-formas/garrafas PET } \\
\text { (transformadores/sopradores) }\end{array}$ \\
\hline
\end{tabular}

Fonte: Levantamento direto nas empresas pesquisadas.

\section{Resultados e discussão}

\subsection{Dinâmica de adoção das normas ISO 9000 nos casos estudados}

Os diferentes elos da cadeia de valor de embalagens PET para bebidas considerados neste estudo, cada um representado por uma grande empresa atuante no Brasil, apresentaram distintos perfis para os motivos associados à adoção do padrão ISO 9000. Para o fabricante de resina PET, a ampliação da capacidade de inovação, a melhoria da qualidade dos produtos e a agregação de valor aos produtos e atividades da empresa foram razões mais importantes do que para o fabricante de pré-formas/garrafas PET (Gráfico 1). Ao contrário, para este último, a orientação estratégica e a 
melhora da imagem da empresa foram fatores expressivamente mais relevantes quando da decisão de adoção.

Gráfico 1 - Principais indutores da adoção do padrão normativo ISO 9000 nos casos dos fabricantes de resina e de préformas/garrafas PET

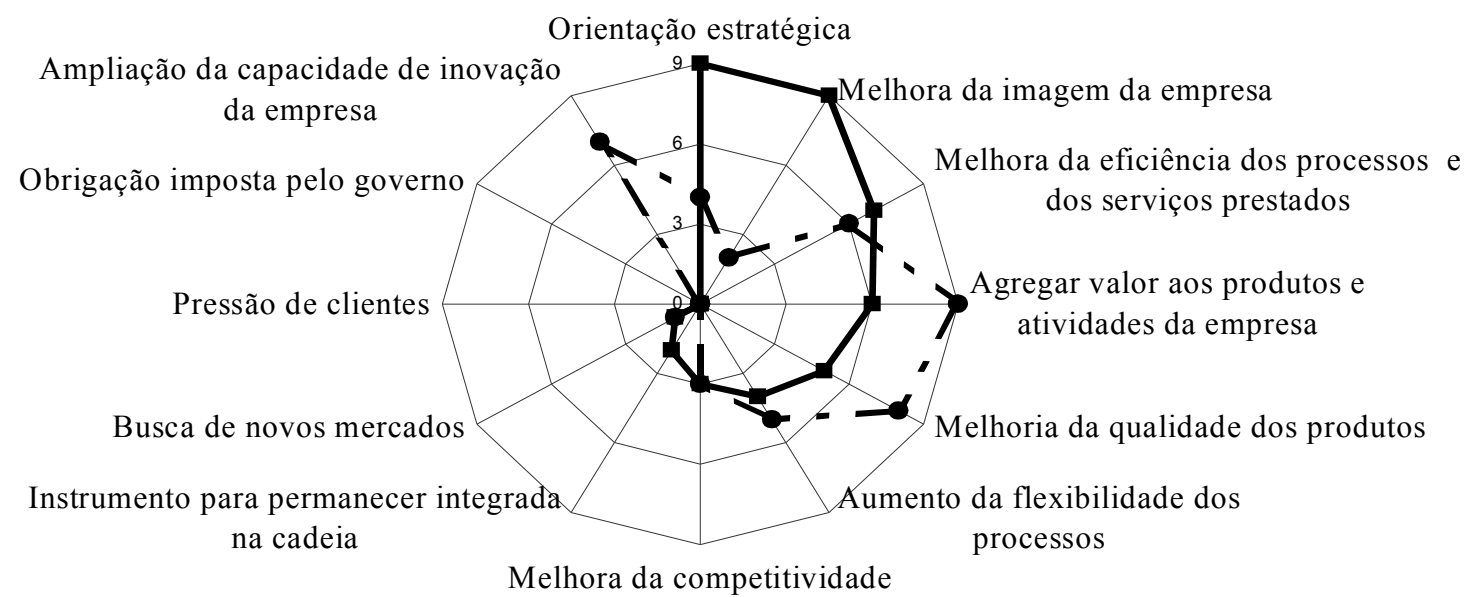

$\longrightarrow$ - Fabricante de resina PET $\longrightarrow$ Fabricante de pré-forma/garrafa PET

Fonte: Levantamento direto nas empresas pesquisadas.

Esses resultados parecem indicar, por um lado, que o fabricante de pré-formas/garrafas PET, cuja matriz localiza-se no Brasil, procurou manter a competitividade e conquistar novos clientes com a abertura comercial, tendo, para tanto, que se alinhar aos padrões internacionais de gestão da qualidade que já estavam disseminados em diversos países do mundo desde a década de 70 . Acrescente-se que o nível de exigência de qualidade no mercado interno não era tão elevado quanto em alguns países do bloco considerado desenvolvido, de modo que uma empresa nacional teria de se esforçar para convencer potenciais clientes estrangeiros ${ }^{3}$ da qualidade de seus produtos e processos, o que poderia ser facilitado com a obtenção de um certificado internacionalmente reconhecido como o ISO 9000.

Diferentemente, o fabricante de resina PET, cuja matriz se localiza em um país desenvolvido do continente europeu, já apresentava reputação internacional, buscando os benefícios associados à disciplina dos sistemas organizacionais e gerenciais para fortalecer aspectos internos, e talvez, alinhar-se a filiais em outros países e à matriz no que diz respeito à gestão da qualidade.

Considerando, agora, as dificuldades enfrentadas pelas empresas analisadas durante a implantação e certificação dos seus sistemas de gestão da qualidade ISO 9000, observam-se

\footnotetext{
${ }^{3}$ Refere-se a clientes não necessariamente localizados no exterior, mas a clientes que, mesmo localizados no Brasil, são, de alguma forma, vinculados a empresas que atuam globalmente.
} 
diferenças não desprezíveis entre o fabricante de resina PET e o fabricante de pré-formas/garrafas PET (Quadro 2).

Quadro 2 - Principais dificuldades enfrentadas pelos fabricantes de resina e de pré-formas/garrafas PET para a obtenção do certificado ISO 9000

\begin{tabular}{lcc}
\hline \multirow{2}{*}{ Dificuldades } & \multicolumn{2}{c}{ Grau (decrescente) } \\
\cline { 2 - 3 } & $\begin{array}{c}\text { Fabricante de } \\
\text { resina PET }\end{array}$ & $\begin{array}{c}\text { Fabricante de pré- } \\
\text { formas/garrafas PET }\end{array}$ \\
\hline Mudanças estratégicas requeridas & 1 & $\ldots$ \\
Mudanças organizacionais requeridas & 2 & 1 \\
$\begin{array}{l}\text { Mudanças nas relações sociais dentro da empresa } \\
\text { Mudanças operacionais requeridas }\end{array}$ & 3 & $\ldots$ \\
$\begin{array}{l}\text { Capacitação técnica/tecnológica em nível gerencial e } \\
\text { operacional }\end{array}$ & 4 & $\ldots$ \\
$\begin{array}{l}\text { Envolvimento da alta administração } \\
\text { Mudança nas relações com fornecedores, clientes e }\end{array}$ & 6 & $\ldots$ \\
$\begin{array}{l}\text { concorrentes } \\
\text { Custos envolvidos no processo de implantação de }\end{array}$ & 7 & $\ldots$ \\
sistemas de gestão da qualidade, de certificação e & & $\ldots$ \\
manutenção do certificado & 8 & 3 \\
\hline
\end{tabular}

Legenda: (1) motivo mais importante; (2) segundo motivo mais importante, e assim por diante.

Fonte: Levantamento direto nas empresas pesquisadas.

O primeiro apresentou um quadro de dificuldades mais extenso e mais acentuado em aspectos estratégicos e estruturais, mas também em aspectos operacionais. O segundo reforçou dificuldades em estrutura, gestão e custos, mas não operacionais. Chamam a atenção dois pontos: as significativas dificuldades quanto à estrutura e gestão e a grande diferença apontada pelas duas empresas em termos da dificuldade com os custos envolvidos no processo de implantação do padrão ISO 9000. Em relação os primeiro ponto, pode-se destacar a provável redefinição de tarefas e responsabilidades, contra o que pode ter havido resistências internas, e as novas competências requeridas, que normalmente demandam esforço de busca e aprendizagem consideráveis, como fatores que contribuíram para o grau de dificuldade percebido. Em ambos os casos, o esforço de adaptação a novas diretrizes, regras e procedimentos de trabalho pode ter sido percebido como dificuldade. Relativamente às dificuldades envolvendo os custos com a implantação da ISO 9000, para o fabricante de resina PET, que obtém uma receita líquida de vendas anual superior à do fabricante de pré-formas/garrafas PET em quase cinco vezes, tal dificuldade foi bem menos importante do que para este último.

Após a implantação e certificação do sistema de gestão da qualidade ISO 9000, ainda restam lacunas, que parecem ser da mesma natureza, no que se refere à garantia da qualidade em ambas as empresas investigadas. Os dois entrevistados ressaltaram a necessidade de melhorias em aspectos relativos aos clientes, especificamente na gestão de suas demandas e atendimento de suas expectativas. Nesse sentido, pode-se ponderar que o tratamento desses assuntos ultrapassa as fronteiras da norma, cabendo à empresa definir a política e os procedimentos de gestão de relacionamentos com clientes. Em itens cobertos pela norma, diferentemente, não foram indicadas 
lacunas, o que faz sentido, uma vez que o fato de a empresa ser certificada se traduz em conformidade com os padrões por ela estabelecidos.

A experiência de implementação de um sistema de gestão da qualidade certificado por normas internacionais, no caso, da série ISO 9000, teve reflexos diferentes para o fabricante de resina e o de pré-formas/garrafas $\mathrm{PET}$ no que tange à absorção dos seus princípios fundamentais. $\mathrm{O}$ fabricante de resina PET destacou que havia, na empresa, a necessidade de desenvolver um ambiente, uma infra-estrutura e um corpo de recursos humanos capacitados, observando prioritariamente, portanto, uma parcela importante dos insumos relacionados com a gestão da qualidade para a obtenção de resultados futuros, em um prazo mais longo. Diferentemente, o fabricante de pré-formas/garrafas PET destacou a melhora dos resultados da empresa. Essa forma genérica de estabelecer objetivos parece dificultar o estabelecimento de metas e indicadores de desempenho que verdadeiramente permitam avaliar os resultados da adoção das normas ISO 9000. Daí, em parte, a necessidade de a empresa mudar o papel da qualidade em sua estratégia de negócios, bem como de reorganizar a estrutura e os processos de administração e sistemas de gestão em função da implantação do referido padrão, passos, sem dúvida, fundamentais para o processo de absorção dos princípios desse padrão normativo.

Esse esforço de absorção, existente no primeiro caso, mas não no segundo, ficou evidente também na adoção de normas e práticas de garantia da qualidade complementares à ISO 9000. O fabricante de resina PET declarou que seu sistema de gestão da qualidade é certificado por outro padrão normativo - OHSAS 18001: 1999, obtido em 2004 - e que a empresa adota práticas de qualidade complementares, incluindo o Programa 5S, o uso de Ferramentas da Qualidade e programas de formação e educação para a qualidade, via treinamentos técnicos. Ao contrário, o fabricante de pré-formas/garrafas PET informou que a empresa não possui certificados de qualidade ligados a outros padrões normativos e nem adota práticas de qualidade complementares àquelas da ISO 9000.

Assim, pode-se inferir que a qualidade, no caso do fabricante de resina PET, é tratada segundo uma dimensão ampliada, para além dos produtos, processos e serviços, envolvendo questões relacionadas com a saúde e segurança do trabalho. Adicionalmente, a obtenção e manutenção do certificado ISO 9000 parecem não ser as finalidades da Função Qualidade, mas sim um esforço necessário, somado à implantação de práticas de qualidade complementares, ao objetivo maior de avançar em direção à qualidade total através da melhoria contínua. $\mathrm{O}$ mesmo já não ocorre, ao menos à época da pesquisa, no caso do fabricante de pré-formas/garrafas PET, para o qual a certificação ISO 9000 era um fim em si mesma, o objetivo central da Função Qualidade. 


\subsection{Impactos intra-organizacionais observados da adoção de normas ISO 9000}

As empresas investigadas apresentaram diferentes perfis de mudanças internas em função da adoção do padrão ISO 9000: o fabricante de resina PET considerou mais importantes mudanças operacionais, relacionadas à pós-fabricação do produto, e estratégico-administrativas, associadas à Função Qualidade, enquanto o fabricante de pré-formas/garrafas PET destacou, além destas últimas, mudanças operacionais relacionadas à documentação e práticas de controle da qualidade em etapas de apoio à fabricação do produto (Gráfico 2).

No entanto, é interessante notar a semelhança, entre as empresas investigadas, quanto à elevada importância atribuída à reavaliação do papel da qualidade na estratégia de negócios. Este resultado era esperado, uma vez que um dos requisitos da implantação desse padrão normativo é a promoção de um sério comprometimento de toda a empresa, desde o nível hierárquico mais elevado até o nível operacional, com sua implementação e manutenção, traduzido na inserção estratégica da qualidade na organização.

Gráfico 2 - Principais mudanças internas em gestão da qualidade promovidas para a obtenção do certificado ISO 9000 nos casos dos fabricantes de resina e de pré-formas/garrafas PET

Mudanças internas decorrentes da adoção do padrão ISO 9000

Reavaliação e alteração de práticas/procedimentos pós-fabricação

Reavaliação do papel da qualidade na estratégia de negócios da empresa

Revisão e alteração de práticas/procedimentos de controle de produtos não-conformes

Reorganização da estrutura e dos processos de administração e sis temas organizacionais

Reformulação da política de qualidade

Alteração das práticas de planejamento, controle e análise de contratos e projetos

Reformulação dos procedimentos de elaboração e controle de documentos

Modificação nas práticas/processos de aquisição; inspeção, ensaios e testes

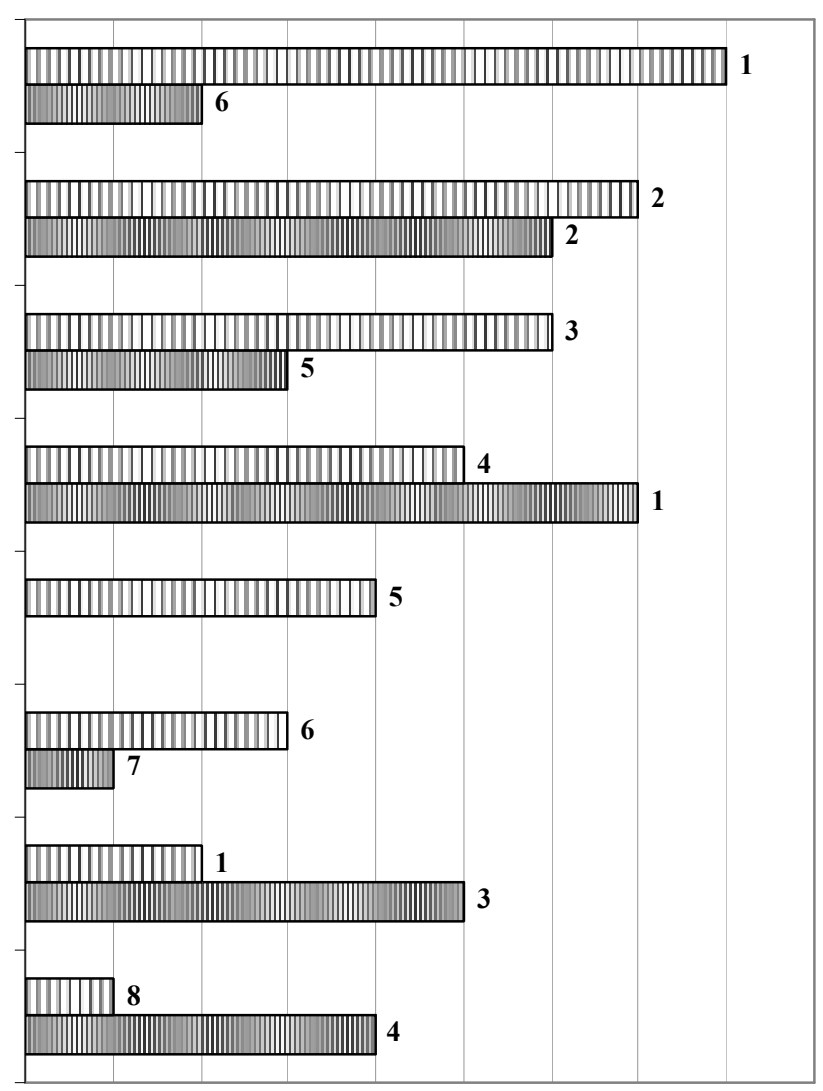

Fabricante de pré-forma/garrafa PET

๑ Fabricante de resina PET

Legenda: (1) mudança mais importante; (2) segunda mudança mais importante, e assim por diante. Fonte: Levantamento direto nas empresas pesquisadas. 
As mudanças observadas na Função Tecnológica, especificamente, como efeito da adoção da norma ISO 9000, em geral foram positivas e muito similares para o fabricante de préformas/garrafas PET em relação ao fabricante de resina PET. Ambos relataram o aperfeiçoamento de tecnologias dominadas pela empresa como opção estratégica adotada; a ampliação do grau de compartilhamento e dos esforços na atividade de inovação tecnológica; a melhora do nível de capacitação tecnológica; e o aumento do grau de especialização tecnológica.

Assim, ambas as empresas pesquisadas parecem buscar melhor aproveitamento das competências disponíveis internamente e relacionamentos tecnológicos vantajosos (dividindo riscos intrínsecos à atividade inovativa e aproveitando sinergias advindas do compartilhamento de recursos complementares), estabelecidos, principalmente com fornecedores e clientes, mas também com agentes externos à cadeia de valor, tais como universidades e centros tecnológicos.

Essas mudanças satisfatórias na Função Tecnológica são indícios de que a hipótese de Quadros (2002); Nadvi e Wältring (2001); Nadvi e Kazmi (2001); Humphrey e Schmitz (2000), entre outros, de que a adoção de normas técnicas internacionais de qualidade possuem impactos positivos sobre o aperfeiçoamento tecnológico das empresas, é verificada na cadeia de embalagens PET para bebidas no Brasil.

\subsection{Impactos interorganizacionais observados da adoção de normas ISO 9000}

O fabricante de resina PET, assim como o fabricante de pré-formas/garrafas PET perceberam um aumento da satisfação (redução de reclamações e ações judiciais, redução da probabilidade de o cliente substituir a empresa por outro fornecedor) e um aumento, porém comparativamente menos significativo, da cooperação técnica (maior propensão a resolver possíveis falhas diretamente com a empresa e ampliação da colaboração para além da esfera produtiva) com o cliente após a adoção das normas ISO 9000 na gestão de seus sistemas de gestão da qualidade. No entanto, diferenças foram observadas nas funções envolvidas na cooperação Qualidade, Tecnologia/Desenvolvimento, Produção, Assistência Técnica, Logística e Comercial, no primeiro caso; Qualidade e Comercial, no segundo. Também foram percebidas variações na forma como os parceiros passaram a valorizar a empresa - participação nas mudanças necessárias, no caso do fabricante de resina PET; confiabilidade, no caso do fabricante de pré-formas/garrafas PET.

Esses resultados mostram, por um lado, que os impactos interorganizacionais positivos observados após a certificação ISO 9000, em ambos os casos, ocorreram principalmente em atividades ligadas à Produção: o crescimento do valor adicionado dos produtos e serviços oferecidos pela empresa e a melhora da imagem da empresa, apontados pelos entrevistados como os 
principais motivos que levaram o fabricante de resina e de pré-formas/garrafas PET, respectivamente, à adoção do padrão normativo ISO 9000, parecem referir-se especialmente à melhoria da qualidade, expressa através da maior satisfação dos clientes. E, por outro, que o fabricante de resina PET apresenta uma atividade de cooperação técnica mais intensa com seus parceiros, inclusive em algumas atividades-chave (Desenvolvimento de Embalagens), relativamente ao fabricante de pré-formas/garrafas PET, apesar de, em nenhum caso, envolver efetivamente atividades de pesquisa para o desenvolvimento de novos produtos.

No relacionamento com fornecedores, padrões distintos foram verificados entre as duas empresas investigadas. O fabricante de pré-formas/garrafas PET negocia aspectos de caráter mais técnico, sobretudo aqueles associados a especificações e requisitos do produto e tecnologias de produção, com impactos no prazo mais curto. Já o fabricante de resina PET, além desses aspectos, trata de atividades cooperativas em atividades não-acessórias, como marketing, redes de trabalho e cooperação informal, o que parece refletir a importância atribuída a fatores e atividades potencialmente geradores de benefícios futuros, de curto e de longo prazo, tais como aquisição de conhecimentos tácitos, consolidação de mecanismos informais de aprendizagem, padronização de metodologias de trabalho e estabelecimento de relacionamentos baseados em confiança e estabilidade.

Cabe destacar a importância atribuída por ambas as empresas à gestão integrada da qualidade ao longo da cadeia de valor como forma de garantir a satisfação do cliente final e de coordenar os vários elos da cadeia. Este entendimento parece ter sido consolidado após a certificação ISO 9000, o que está relacionado com os princípios de garantia da qualidade associados a essa norma.

Quanto ao modo de estabelecer esses relacionamentos com clientes e fornecedores, é importante salientar uma diferença fundamental: o fabricante de resina PET freqüentemente utiliza cooperação formal, enquanto o fabricante de pré-formas/garrafas PET, contrato (Quadro 3). A cooperação formal envolve o estabelecimento de acordos codificados, regulados, com parâmetros definidos de duração, escopo, direitos e obrigações associados a cada empresa participante, que se prolongam por um intervalo de tempo normalmente mais longo que o contrato, sobretudo à medida que o relacionamento matura e se desenvolve credibilidade e confiança mútua entre as empresas parceiras. Já o contrato confere maior flexibilidade às empresas, que podem estabelecer relacionamentos mais curtos e limitados com um conjunto mais amplo de outros parceiros. Essas características permitem ao fabricante de resina PET estabelecer o desenvolvimento de novas competências, por exemplo, como objetivo central dos relacionamentos em que se engaja, ao contrário do fabricante de pré-formas/garrafas PET, que busca essencialmente aperfeiçoamentos das competências que já domina. 
Quadro 3 - Principais mudanças na política de relacionamentos dos fabricantes de resina e de pré-formas/garrafas PET com fornecedores e clientes, após a obtenção do certificado ISO 9000

\begin{tabular}{|c|c|c|}
\hline \multirow{2}{*}{$\begin{array}{l}\text { Mudanças na política de } \\
\text { relacionamentos }\end{array}$} & \multicolumn{2}{|c|}{ Qualificação da mudança } \\
\hline & Fabricante de resina PET & $\begin{array}{l}\text { Fabricante de pré- } \\
\text { formas/garrafas PET }\end{array}$ \\
\hline $\begin{array}{l}\text { Preocupação central em relação aos } \\
\text { parceiros }\end{array}$ & $\begin{array}{l}\text { capacidade de cumprir as tarefas } \\
\text { que lhes foram atribuídas }\end{array}$ & $\begin{array}{l}\text { capacidade de cumprir as tarefas } \\
\text { que lhes foram atribuídas }\end{array}$ \\
\hline Número de fornecedores & Reduziu & aumentou \\
\hline Número de clientes & Aumentou & aumentou \\
\hline Tipo de relacionamento & $\begin{array}{l}\text { estável, de longo-prazo, mas } \\
\text { mantendo a independência dos } \\
\text { parceiros }\end{array}$ & $\begin{array}{l}\text { estável, de longo-prazo, mas } \\
\text { mantendo a independência dos } \\
\text { parceiros }\end{array}$ \\
\hline Modo de formalizar o relacionamento & cooperação formal & contrato \\
\hline Objetivo central do relacionamento & desenvolver novas competências & $\begin{array}{l}\text { aperfeiçoar atuais competências } \\
\text { da empresa }\end{array}$ \\
\hline $\begin{array}{l}\text { Capacidade de gestão dos } \\
\text { relacionamentos }\end{array}$ & Melhorou & melhorou \\
\hline
\end{tabular}

Fonte: Levantamento direto nas empresas pesquisadas.

Por fim, ambas as empresas pesquisadas avaliaram positivamente os impactos interorganizacionais derivados da implantação e certificação de seus sistemas de gestão da qualidade ISO 9000, apesar de perceberem alguns efeitos significativamente diferentes, tendo em vista as motivações iniciais para a adoção, a estrutura e as capacitações disponíveis.

\section{Conclusões e recomendações}

Tratou-se, neste artigo, da dinâmica do processo de adoção do padrão normativo ISO 9000 e de alguns de seus principais impactos no âmbito do setor de embalagens PET para bebidas no Brasil. Os resultados obtidos a partir de dois estudos de caso indicaram claros impactos positivos da adoção do padrão ISO 9000 sobre aspectos internos da empresa, especialmente na esfera produtiva, mas também, embora em menor intensidade, em aspectos tecnológicos. De fato, tanto o fabricante de resina quanto o de pré-formas/garrafas PET conheceram mudanças significativas na estrutura, organização, gestão e, sobretudo, operação do sistema da qualidade nas empresas investigadas. Estas mudanças parecem tê-las capacitado melhor, de modo que passaram a cooperar mais, especialmente em aspectos técnico-operacionais, com fornecedores e clientes, mas não sinalizam um efetivo aprofundamento dos laços de cooperação em áreas-chave como $\mathrm{P} \& \mathrm{D}$, design, marketing e distribuição.

Assim, foi possível verificar que as proposições assumidas neste estudo confirmaram-se parcialmente, dependendo, em algum grau, da relevância atribuída a aspectos internos quando da decisão de adoção e dos processos de implantação e gestão da ISO 9000, por um lado, e do elo da cadeia de embalagens PET a que as empresas pertencem e da nacionalidade de suas matrizes, por outro. 
Faz-se necessário destacar, aqui, que esses resultados estão condicionados a limitações intrínsecas às variáveis analisadas e aos métodos utilizados. No que se refere às primeiras, são complexas e sujeitas à atuação de fatores intervenientes ambientais e setoriais, que inspiram cuidados na leitura, interpretação e utilização posterior dos resultados. Já quanto ao método utilizado, caracterizado por uma pesquisa qualitativa, de caráter exploratório, realizada por meio de estudo de dois casos, utilizando formulário eletrônico do tipo survey para a coleta de dados, apesar de ser considerado o mais adequado para este estudo, é contestado por diversos pesquisadores quanto à sua confiabilidade ${ }^{4}$.

Os casos investigados neste estudo representaram uma parcela considerável, em termos de volume de produção e participação de mercado dos respectivos elos da cadeia de valor de embalagens PET para bebidas no Brasil. Ainda que não apresente representatividade estatística, no entanto, este trabalho contribuiu para o melhor delineamento de futuros trabalhos sobre o tema. Nesse sentido, recomendam-se dois tipos de abordagens: estudos de caso exploratórios similares com um conjunto maior (quatro a dez casos) e mais heterogêneo (em termos de tamanho, origem do capital controlador, elo da cadeia de valor, geografia de mercados atendidos, etc.) de empresas e utilização de questionários abertos; ou o uso de métodos baseados em análise estatística aplicada a uma amostra grande e representativa da população a ser investigada.

Com relação às variáveis intervenientes, recomenda-se analisar fatores reconhecidamente importantes, como características do setor e da natureza do produto, que poderiam fornecer indícios relevantes de semelhanças e diferenças entre grupos distintos de empresas de um mesmo setor e de setores diferentes.

No que tange às implicações do estudo para a prática empresarial, cabe destacar, considerando importantes restrições em função de especificidades associadas à organização e seu entorno, que:

a) não existem variadas "versões" de sistemas de gestão da qualidade construídos com base na ISO 9000, de modo que a diferenciação em relação aos concorrentes que as empresas buscam ao adotar um padrão normativo como esse aqui abordado não depende exclusivamente dele, mas sim do modo como se insere no ambiente organizacional (está integrado a uma política de qualidade ampliada, que conta com outros instrumentos e práticas para a gestão da qualidade? Existe uma cultura para a qualidade disseminada por toda a empresa que favoreça sua implantação e manutenção? Os parceiros da cadeia

\footnotetext{
${ }^{4}$ Algumas limitações apontadas para esses métodos incluem: a) os dados incorporam, em alguma medida, a subjetividade do pesquisador e das unidades pesquisadas; b) os estudos exploratórios não se prestam a explicar, de maneira cabal, os fenômenos enfocados, mas apenas a gerar elementos para a formulação de possíveis hipóteses; c) os estudos de caso revelam dados concretos que, sem dúvida, contribuem para a pesquisa sobre o tema, mas restritos a condicionantes específicos das unidades analisadas e dos contextos em que se inserem, dificultando generalizações possivelmente relevantes; e d) o formulário do tipo survey reduz a flexibilidade da coleta de dados, uma vez que é formado, em grande parte, por questões estruturadas, que condicionam a resposta do entrevistado a uma das opções disponíveis.
} 
de valor valorizam adequadamente o certificado de maneira a intensificar e diversificar ações conjuntas?);

b) de forma similar, a flexibilidade em relação às mudanças no mercado pretendida pelas empresas que decidem adotar um padrão normativo como o ISO 9000 não depende exclusivamente dele, mas também do modo como são entendidas e utilizadas essas normas na empresa: se apenas como regras que exigem excessiva documentação formal dos processos organizacionais, tornando morosa a resposta a mudanças no mercado; ou como regras explícitas que disciplinam os sistemas organizacionais e gerenciais sob os quais a empresa funciona, reduzindo a dependência hierárquica nas operações (menor necessidade de supervisão), facilitando o processo de formação de memória organizacional (melhor codificação do conhecimento) e, portanto, aumentando a velocidade de reação a mudanças no mercado.

Em conclusão, não se pode afirmar que os impactos organizacionais da adoção das normas ISO 9000 são estritamente positivos ou negativos. Como foi preliminarmente constatado, existem vários fatores endógenos e exógenos que interferem tanto no processo de adoção quanto nos impactos associados. Cabe a cada empresa, observando as características e limitações próprias e do seu entorno, construir um ambiente integrado e propício, em termos de estratégia e políticas, cultura e recursos humanos, infra-estrutura e modo de operação, ao bom aproveitamento da certificação ISO 9000.

\begin{abstract}
The main purposes of this study are to characterize the dynamics of the adoption of ISO 9000 normative standards and analyze their impact in internal and external aspects of companies. By assessing data and information provided by selected packaging companies working with PET bottles in Brazil, it was studied, on the one hand, the main causes (motivations and needs) for the adoption of such standards, the difficulties faced throughout the implementation process, identified gaps and similar or complementary initiatives adopted after certification; and, on the other hand, the main strategic, managerial and operational deriving changes, mainly those concerning the relationship with direct suppliers and clients as to Technological and Productive functions. The investigation of these questions involved the analyses of two cases - the largest national producers of PET resin and PET bottles. The comparative analyses of both cases revealed, in general, different profiles in the adoption of ISO 9000 standards and in deriving impacts, except for the fact that they concentrate on the productive realm. One possible explanation for such finding is the one related to the existence of a quality program which surpasses the scope and limits of ISO 9000 and of an environment and culture of quality that is spread throughout the company in the case of the resin producer, but not in the case of PET bottle manufacturer. Another explanation refers to the intensity and diversity of cooperative activities in those companies which are significantly higher in the first case if compared to the second case. A third explanation concerns the effect of various environmental and sector-related interfering factors such as the nationality of the holding company and the chain link the companies are part. Preliminary comparisons with national and international companies from different industrial sectors enabled us to confirm that sector-related factors,
\end{abstract}


distinctive socioeconomic contexts and institutional support infrastructure in different countries interfere in the adoption of ISO 9000 standards. However, even though there may be diverging organizational impacts to companies, since the dynamics of adoption are different, the management systems based on ISO 9000 do not have varied "versions".

Key-words: organizational change; ISO 9000 normative standards; packaging; quality guarantee.

\section{Referências}

AZEVEDO, A. B. A. de. As implicações da difusão de normas técnicas para o aperfeiçoamento tecnológico da indústria moveleira. Campinas, SP, 2003. Dissertação (Mestrado em Política Científica e Tecnológica), Universidade Estadual de Campinas, 2003.

DYER, J. H.; SINGH, H. The relational view: cooperative strategy and sources os interorganizational competitive advantage. Academy of Management Review. New York: Academy of Management, v.23, n.4, p.660-679, oct. 1998.

FIGUEIREDO, P, N. Technological capability - accumulation paths and the underlying learning processess: a review of empirical studies, 2001. Disponível em: <http://copenhagen.jibs.net/LitReview/2001/2001_1_26.pdf>. Acesso em: 24 jul. 2003.

GOTZAMANI, K.; TSIOTRAS, G. D. The true motives behind ISO 9000 certification: their effect on the overall certification benefits and long-term contribution towards TQM. International Journal of Quality and Reliability Management. Bradford: MCB UP, v.19, n.2, p. 151-169, 2002.

HUMPHREY, J.; SCHMITZ, H. How does insertion in global value chain affect upgrading in industrial clusters?. In: RESEARCH PROJECT “THE INTERACTION OF LOCAL AND GLOBAL GOVERNANCE”: IMPLICATIONS FOR INDUSTRIAL UPGRADING, [2001], Brighton. Output of the ... Brighton: University of Sussex. Institute of Development $\quad$ Studies, $\quad[2001], \quad 16 \mathrm{p}$ Disponível em: http://www.ids.ac.uk/ids/global/pdfs/JHHSRegStudies25jun02.pdf`. Acesso em: 16 jun. 2003.

HUMPHREY, J.; SCHMITZ, H. Governance and upgrading: linking industrial cluster and global value chain research. IDS Working Paper, 120, Brighton: Institute of Development Studies, 2000.

MADHOK, A. Transaction costs, firm resources and interfirm collaboration. In: DRUID SUMMER CONFERENCE ON COMPETENCE, GOVERNANCE AND ENTREPRENEURSHIP, 1998, Bornholm. Paper submmited to..., Bornholm: Copenhagen Business School, 1998, 40p. Disponível em: < http://www.druid.dk/conferences/summer1998/conf-papers/madhok.pdf $>$. Acesso em: 12 mai. 2004.

MESSEGHEM, K. Implications organisationnelles des normes ISO 9000 pour les petites et moyennes entreprises. Finance Contrôle Stratégie. Paris, France: Éditions Economica, v.4, n.3, sep. 2001, p. 183 - 213.

NADVI, K.; KAZMI, S. Global standards and local responses. In: WORKSHOP ON THE IMPACT OF GLOBAL AND LOCAL GOVERNANCE ON INDUSTRIAL UPGRADING, 13-17 feb. 2001, Brighton. Draft for..., Brighton: University of Sussex. Institute of Development Studies, 2001, 50p. Disponível em: $<$ http://www.ids.ac.uk/ids/global/pdfs/khalidsajid.pdf>. Acesso em: 16 jun. 2003.

NADVI, K., WÄLTRING, F. Global standards: implications for local and global governance. In: WORKSHOP ON THE IMPACT OF GLOBAL AND LOCAL GOVERNANCE ON INDUSTRIAL UPGRADING, feb. 2001, Brighton. Proceedings..., Brighton: University of Sussex , Institute of Development Studies, 2001.

QUADROS, R. Global quality standards, chain governance and the technological upgrading of Brazilian autocomponents producers. IDS Working Paper, Brighton: Institute of Development Studies, n.156, may 2002. Disponível em: <http://www.ids.ac.uk/ids/bookshop/wp/wp156.pdf>. Acesso em: 02 jun. 2003.

ROGERS, E.M. Diffusion of innovations. 3. ed. New York: Free Press, 1983, 453p.

ROTH, J. L. Impactos da ISO 9000 sobre a gestão das empresas: inferências a partir de três estudos de casos. Porto Alegre, RS, 1998. Dissertação (Mestrado em Administração), Universidade Federal do Rio Grande do Sul, 1998.

STEINMULLER, W.E. The role of technical standards in co-ordinating the division of labour in complex system industries. In: PRENCIPE, A, DAVIES, A.; HOBDAY, M. (Eds.). The business of systems integration, Science and 
Technology Policy Research Unit, University of Sussex, UK, Disponível em: $<$ http://www.druid.dk/conferences/winter2003/ Paper/Steinmueller.pdf>. Acesso em: 23 de abr. de 2003, cap.7, 24p.

SZYSZKA, I. Implantação de sistemas de qualidade ISO 9000 e mudanças organizacionais. Porto Alegre, RS, 2001. Dissertação (Mestrado em Administração), Universidade Federal do Rio Grande do Sul, 2001. $205 f$.

VONDEREMBSE, M. A.; WHITE, G. P. Operations management: concepts, methods, and strategies. 3ed. Minneapolis/St. Paul: West Pub. Co., 1996.

WOLFE, R. A. Organizational innovation: review, critique and suggested research directions. Journal of Management Studies. Oxford: Blackwell Publishers, v.31, n.3, p.405-431, may 1994.

\section{Dados completos de todos os autores:}

\section{Nome completo: Milena Yumi Ramos}

Filiação institucional: Fundação de Amparo à Pesquisa do Estado de São Paulo - FAPESP

Departamento: Assessoria Técnica de Indicadores de Ciência, Tecnologia e Inovação

Função ou cargo ocupado: Assistente Técnica

Endereço completo para correspondência (bairro, cidade, estado, país e CEP):

Rua Pio XI, $1.500-3^{\circ}$ andar

05468-901 - Alto da Lapa

São Paulo/SP

Telefones para contato: (11) 3838.4218 (trabalho); (11) 8268.3097 (pessoal)

e-mail: myramos@fapesp.br (trabalho); my_ramos@yahoo.com.br (pessoal)

\section{Nome completo: Roberto Sbragia}

Filiação institucional: Universidade de São Paulo

Departamento: Faculdade de Economia, Administração e Contabilidade. Departamento de Administração

Função ou cargo ocupado: Professor Titular

Endereço completo para correspondência (bairro, cidade, estado, país e CEP):

Av. Prof. Luciano Gualberto, 908 - FEA 1, Piso Superior, Sala B 103

05508-900 - Cidade Universitária

São Paulo/SP

Telefones para contato: (11) 3818.4011 ; (11) 3091.5969

e-mail: rsbragia@usp.br 